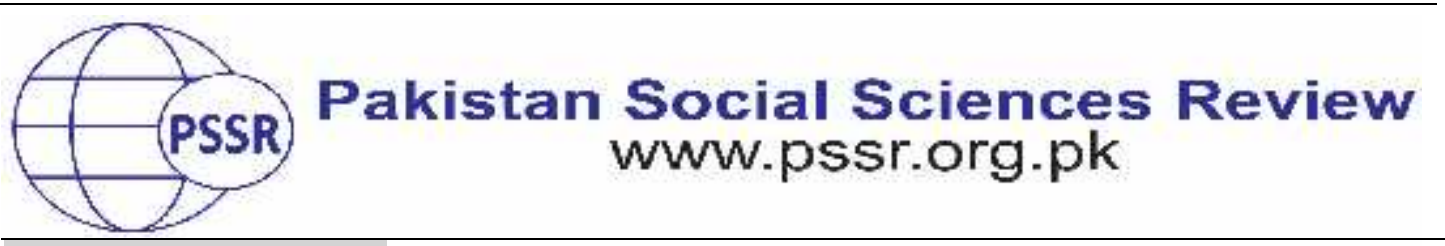

RESEARCH PAPER

\title{
A Challenges of Using ICT at Secondary Schools in Rawalpindi
}

\author{
Humna $^{1}$ Dr. Qaisara Parveen ${ }^{2}$ Dr. M. Imran Yousuf ${ }^{3}$
}

1. M. Phil Scholar, Department of Education, Faculty of Social Sciences, Pir Mehr Ali Shah Arid Agriculture University Rawalpindi, Pakistan

2. Assistant Professor, Department of Education, Faculty of Social Sciences, Pir Mehr Ali Shah Arid Agriculture University Rawalpindi, Pakistan

3. Chairman, Department of Education, Faculty of Social Sciences, Pir Mehr Ali Shah Arid Agriculture University Rawalpindi, Pakistan

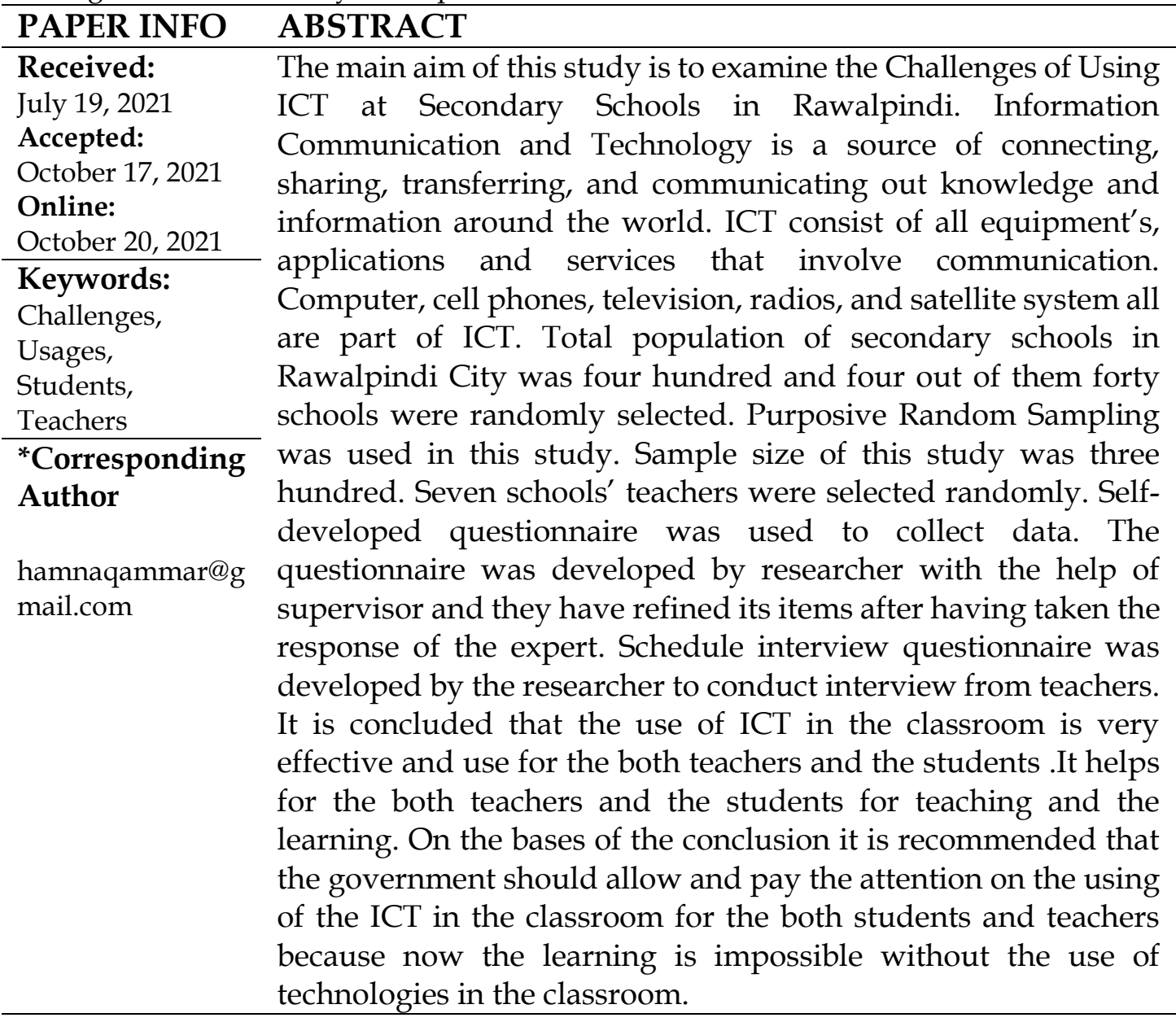

\section{Introduction}

Our educational system needs to assess its main concern and understand that learning should not be matched with cramming. We take self-importance that our educational system is far more highly developed and progressive in terms of 
academic standards in comparison with the U.S.A or U.K. But in terms of originality independent study and an objectives of education in a country like India, which has a wonderful heritage and can boast of variety in geography, culture, values and beliefs very hardly ever seen in this wide world, it should be to educate a student of the value system which is very important to live a successful life (Bhardwaj, A 2016).

Januizewski and Molenda, (2008) argued that Information and Communication Technologies (ICTs) are essential adding into current technology. ICTs comprise of internet, television, radio, mobile, networks, etc. which are performing fundamental role in different fields such as health, education, entertainment. In the field of education many social, cultural, technical, and economic problems has been confronted since the beginning of this century. Educational technology is helping in eradicating all these problems by rising new ways, models and technologies which are making learning and teaching more easily and simple. Modern technologies are giving possibilities to maintain education crossways to the curriculum and present opportunities for successful communication between teachers and learners in ways that have been not been possible before Hassan, T. U., \& Sajid, A. R. (2012). Toffler (1991), "The illiterate rate of 21st century, will not be those who cannot read and write, but those who cannot learn, unlearn and relearn." (p.7). ICTs suggests an extraordinary opportunity for the delivery styles. "Besides Education for All," "Core Work Skills for All ." and " Lifelong Learning for All”, are the basic educational and training necessities in latest global economy as defined by the International Labor Organization ( Tinio,2003,p3) .

Information Communication and Technology (ICTs) came out as a combination of truly powerful tools for all the improvement, transformation, and development in education. Development in making of education most powerful fast for the educational importance, which are aided by the practice of different ICTs in sort to help in converting learning and teaching into an active, attracting, delighting and dynamic procedure that is close to routine life. In light of this introduction of ICTs into educational settings such as classroom across of the world during last few years. The true successful ICTs integration in the system of education is compound of multifaceted system that fully devotes to condition of plenty basic principal but also the term of technology, effective pedagogy, readiness of institutions, competency of teachers, curriculum and long-run funding etc. In this way, new ideas and actions for the increase in information spreading and meeting the challenges are embodied by the Information Communication Technologies (ICTs).

Noor-ul-Amin, (2013) opines that the area of the education has been affected by ICT which have certainly affected the learning, research, and teaching (Yusuf, 2005). The huge compact of study has proved the benefits to the quality of the education. (Al-Ansari, 2006). The ICT have the possibility to innovate, encouragement, set upend grow deeper the skills, to encourage and to keep students and to help to communicate school know-how to work practices, to make economic possibility for tomorrow's workers ,helping schools transform and as well as to increase teaching also.( Davis and Tearle,1999;Lemake and Coughlin,1998;cited by Yusuf,2005). As (Jhurree,2005) says that much has been reported and said about the 
contact of technology specially computer in the education .Primarily computer were only used to teach the computer programming but with the growth of the microprocessor in the early of 1970s saw the introduction of reasonable microcomputers into the schools at a speedy rate.

The present finding was to see the use of ICT in school. How ICT can help in improving the learning of the understudies. How ICT is helping the understudies to show signs of improvement their learning and improving their skills. ICT additionally encourages the understudies to utilize the innovation in legitimate and positive manner. It likewise advises the understudies to utilize innovation in study hall and which innovation is ideal to use in homeroom. We should assume a significant job in advancing the uses and the advantages of ICT. We as a whole ought to about the positive and negative effect of utilizing ICT in incorrect manner. Everybody should demoralize the negative utilization of ICT in the public. Various courses ought to be led at national and universal levels.

\section{Review of Literature}

ICT stands for "Information communication and technology". It refers to technologies that provide access to information through telecommunication. It is similar to Information Technology (IT) in any case, centers principally around correspondence advancements. This incorporates the web, remote organizations, mobile phones and other correspondence mediums. It implies we have more freedoms to utilize ICT in educator preparing programs now days and work on nature of instructor for instruct viably. As indicated by UNESCO "ICT is a logical, innovative and designing discipline and the board strategy utilized in taking care of data, its application and relationship with social, financial and social matters". Educator is the principle part of the instructive field in our general public. He more works for the improvement level of our general public in the each field. Gifted instructors can make the imaginative understudies in type of the great social laborer, legislator, artist, thinker and so forth for the general public. Ratheeswari, K. (2018).

Instructors can assume an amicable part with the student. The quick advancement in innovation has made inventively changes in the way we live, just as the requests of the general public.

Perceiving the effect of new advancements on the work environment and daily existence, the present educator training establishments attempt to rebuild their schooling programs and homeroom offices, to limit the educating and learning innovation hole among today and what's to come. ICTs are rolling out unique improvements in the public eye. They are affecting all parts of life. The impacts are felt more furthermore, more at schools. Since ICTs give the two understudies furthermore, instructors with more freedoms in adjusting learning what's more, instructing to individual requirements, society is, driving schools appropriately react to this specialized development. 


\section{Digital technologies as objectives for learning}

\section{ICT as an objective of learning for students}

To flourish in a computerized world, understudies should be furnished with a decent blend of abilities, including advanced capability. Having a decent degree of education, numeracy and critical thinking abilities in innovation rich conditions empowers people to move from rudimentary employments of Web to more broadened and complex uses that permit them to benefit as much as possible from advanced innovations. Proof from the Abilities Viewpoint 2019, in view of work area based exploration, shows that adjusting the school educational program to changing abilities necessities to assist with creating 21st century abilities (for example inventiveness, basic reasoning, advanced capability) since the beginning, has been one of the methodologies utilized in OECD nations to make solid establishments for long lasting learning and backing people in adjusting to advancing abilities prerequisites. (OECD, 2019).

\section{ICT as an objective of learning for teacher}

As digital tools progressively enter schools and classrooms, understanding teachers' knowledge about technology integration for teaching is crucial to provide the required support to help develop teachers' digital competence (Xiong, 2020). To tackle the need for teachers to enhance their ICT skills for instructional use (or application), OECD countries have relied on a range of policies, including the development of national plans to promote this goal, compulsory training, national accreditation standards or national certification for teachers (OECD, 2019).

\section{Hypotheses}

Following were the hypothesis of this study

1. There is no significance difference between mean scores of control group and experimental group.

2. There is no significance between difference mean scores of pre - test and posttest.

3. There is no significance difference between mean scores of experimental posttests.

4. There is no significance difference between mean scores of control group.

\section{Material and Method}

\section{Research Design}

This study was experimental in nature. Open survey method was used in this research to collect the data. An experiment was conducted in this research, the experiment was conducted on the school. For this Pre and Post test was conducted 
after comparing the results of both tests we concluded that students learns more with use and help of technological tools.

The population of this study was all secondary schools of Rawalpindi City. Target population of this study was students and teachers at private secondary level schools of Rawalpindi City.

The sample was taken from population size. The sample technique used in this research was purposive sampling and it is non -probability sample type of sampling. Four hundred and four were the total population of research study. Out of them forty schools were randomly selected. Three hundred were sample size of the study. Seven teachers were randomly selected for the interview.

\section{Instrument}

The researcher used questionnaire and interview to collect data. Questionnaires were design such that each question will be related to a given research question and the topic. Questionnaire was prepared considering previous literature review. Closed ended questions were used. Questionnaire was developed considering previous literatures. Questionnaire was developed by the researcher herself. Self - developed questionnaire was used to collect the data.

Interview guide was used to collect primary data. Face-to-face interview guide was set up with sets of outlined questions about issues to be explored. The outlined questions were meant to guide and make sure that all the relevant topics are covered. Pilot testing means to check the validity and reliability of the instruments. In pilot testing 10 students were taken to check the validity and reliability. The alpha value of the instrument was 0.07 and validity was check by the table of specification. Reliability was checked with the help of $21 \mathrm{k}$ formula.

Following was the procedure of this experiment: First of all a permission letter was signed by the supervisor to give researcher a permission to researcher to conduct experiment. Then researcher went to the selected schools and meet school principle to discuss with him about the importance of conducting the experiment. After discussing with principle researcher met the subject teacher to know about the class, students and topics which she was teaching them. Then researcher went into class 10 and firstly introduce herself to the class. Then researcher has divided the students into two different group one was control group and the other was experimental group. For control group Post test was conducted in that no treatment was given to the students and the test was conducted. The other group was experimental group , for this group Pretest was conducted, before taking the test the researcher first teach the students with new methods and use of technology. The researcher prepared the power point presentation to explain the lesson more creatively ,some videos were also showed to the students so that they can understand more effectively with help of multimedia. Then after one week the researcher took the test of these students and finds the results. After comparing results of both the researcher came to know that 
the students learnt more with the help of use of technology and use of technological tools the students leant more effectively.

\section{Results and Discussion}

The data was collected from the respondent. Then data was analyzed with the help of using SPSS version 24. The analysis includes both descriptive and inferential analysis. For the descriptive analysis, the researcher used frequency and percentage of the overall population in the demographic background. It is also used to determine the mean, standard deviation frequency and percentage. In inferential statistics correlation and paired (t-test) were used to analyze the research findings.

Table 1

To review the role and relevance of technology with academic achievement of the students: pre-test and post-test

\begin{tabular}{llll}
\hline Sr.no & Statement & Mean & St. Deviation \\
\hline 1 & Pre-Test & 13.72 & 16.00 \\
\hline 2 & Post-Test & 2.100 & 1.365 \\
\hline & Total & 15.82 & 17.365 \\
\hline
\end{tabular}

This table shows the Mean and Standard Deviation scores of Pre and Post test. The result of pre-test mean score is 13.72 and means score of post test is 2.100. The standard deviation score of pre test was 16.00 and 1.365 was standard deviation score of post-test.

Table 2

Pre-Test table

\begin{tabular}{lccc}
\hline Sr & Marks & Frequency & Percentage \\
\hline 1. & 10 & 2 & 6.5 \\
\hline 2. & 11 & 4 & 12.9 \\
\hline 3. & 12 & 3 & 9.7 \\
\hline 4. & 13 & 4 & 12.9 \\
\hline 5. & 14 & 1 & 3.2 \\
\hline 6. & 14 & 3 & 9.7 \\
\hline 7. & 15 & 7 & 22.6 \\
\hline 8. & 16 & 3 & 9.7 \\
\hline 9. & 17 & 3 & 9.7 \\
\hline 10. & 18 & 5 & 6.6 \\
\hline Total & & 30 & 96.8 \\
\hline
\end{tabular}

In table pre test scores their frequencies and percentage were discussed. In this marks were showed from lowest marks obtained to highest marks obtained. The lowest marks were 10 its frequency was 2 and percentage was 6.5 and similarly the highest marks were 18 and its frequency was 5 and its percentage was 6.6. 
Table 3

Posts -Test

\begin{tabular}{|c|c|c|c|}
\hline Sr & Marks & Frequency & Percentage \\
\hline 1. & 12 & 1 & 3.2 \\
\hline 2. & 14 & 2 & 6.5 \\
\hline 3. & 15 & 7 & 22.6 \\
\hline 4. & 16 & 9 & 29.0 \\
\hline 5. & 16 & 7 & 22.6 \\
\hline 6. & 17 & 4 & 12.9 \\
\hline 7. & 17 & 3 & 10 \\
\hline 8. & 18 & 2 & 5.9 \\
\hline 9. & 18 & 2 & 5.9 \\
\hline 10. & 19 & 1 & 2.9 \\
\hline \multicolumn{2}{|c|}{ Total } & 30 & 96.8 \\
\hline
\end{tabular}

This table shows the result of post -test. Lowest marks were 12 and its frequency was 1 and its percentage was 3.2 similarly the highest marks were 19 and its frequency was 1 and its percentage was 2.9.

Table 4

Paired T-Tests

\begin{tabular}{ccccccccc}
\hline & Mean & $\begin{array}{c}\text { Std. } \\
\text { Deviation }\end{array}$ & $\begin{array}{c}\text { Std. } \\
\text { Error }\end{array}$ & $\begin{array}{c}\text { Mean } \\
\text { Lower }\end{array}$ & Upper & T & DF & $\begin{array}{c}\text { Sig.2 } \\
(2 \text { tailed) }\end{array}$ \\
\hline $\begin{array}{c}\text { Pair } 1 \\
\begin{array}{c}\text { Pretest- } \\
\text { post- } \\
\text { test }\end{array}\end{array}$ & -2.283 & 3.393 & .619 & -3.550 & -1.016 & -3.686 & 29 & .001 \\
\hline
\end{tabular}

95 Confidence Interval Of the Difference

There was a significant difference in the scores for pre and post test. The mean scores was -2.283, Std. Deviation 3.393, Std Error Mean was .619, T value was -3.686, DF value was 29 and Sig.2 (2 tailed) was .001

Specifically, ICTs have affected on instructive practice in training to date in very little ways yet that the effect will develop impressively in years to come and that ICT will turn into a solid specialist for change among numerous instructive practices. Extrapolating current exercises and practices, the proceeded with use and advancement of ICTs inside training will strongly affect ICT and showing learning process; quality and availability of instruction; learning inspiration, learning condition and ICT utilization and scholarly execution.

The selection and utilization of ICTs in instruction positively affect educating, learning, and research. ICT can influence the conveyance of instruction and empower more extensive access to the equivalent. Furthermore, it will expand adaptability with the goal that students can get to the instruction paying little mind to time and land boundaries. It can impact the way understudies are instructed and how they 
learn. It would give the rich condition and inspiration for showing learning process which appears to profoundly affect the way toward learning in instruction by offering new potential outcomes for students and instructors. These potential outcomes can affect understudy execution and accomplishment. Additionally, more extensive accessibility of best practices and best course material in training, which can be shared by methods for ICT, can cultivate better educating and improved scholastic accomplishment of understudies. The general writing proposes that fruitful ICT mix in training.

In the previous researches we have found that the less importance was given to the use of ICT tools and on its implementations. Tools of ICT were not clearly defined but in the present study it was main focus of the researcher to high light the main tools used in the field of ICT and how can teacher and students adopt them and use them in their teaching and learning process.

When we look at the advantages of using ICT in our teaching and learning process, we came to know that ICT has very effective impact on learning and teaching process. When we look for student's point of view, we came to know that ICT provide us to use different new and least technologies in classroom. Whenever students face problem in searching, they can easily check from Google and search it in more simple way. ICT provide different websites from where they can search and find material. ICT also helps the teachers to improve their teaching skills. ICT provides different tools from where teachers can easily adopt and do their work. During lecture in class teacher can easily search anything from net with help of ICT and can also in encourage students to use it.

\section{Conclusion}

Information and communication technology are taking part in a big role in education. ICT will create teaching and learning method more practical and easier. Teaching and learning have become student focused because of ICT. Students are playing higher victimization ICT tools instead of victimization ancient strategies. During this twenty first century a capability to figure with ICT is changing into necessary in each field significantly in education. ICT and education are like 2 sides of same coin. The fusion of ICT and education has become ICT education. It will facilitate students to find out and academics to show a lot of effectively. It is expected that there will be several edges for each the learner and the teacher.

Information Technology offers Muslims the opportunity to realize Muslim education from their homes through virtual categories. Muslim games and videos square measure accessible for kids to find out Islam. This interactive software encourages Muslim youngsters to find out Islam. Today, each Muslim and no Muslim will listen not solely to Muslim talks by far-famed researchers of the Muslim world however will participate in on-line discussions on numerous Muslim topics. They need the chance to raise queries and convey their perceptions. The significance of IT in Islam is punctually acknowledged within the Muslim world. From the perspective of the researchers, the Muslim world should generate a focused on-line accessible 
Islamic library to translate Muslim literature into each language for the world society. This research was conducted to see the challenges and usage of ICT at secondary levels schools in Rawalpindi. The data showed that each lecturers and students used ICT in their everyday lives, for both, the educational and non-academic functions. Majority of the scholars and lecturers have access to a private ICT device equipped with net property and that they use it for various functions from act with different too to finishing assigned task by their lecturers. The study additionally found each the scholars and lecturers believed that ICT could be an important tool to maximized learning in school rooms however students believed that their teachers' use of ICT was least inventive and students wished their teachers to travel on the far side PowerPoint presentation and showing videos within the schoolroom, that is victimization ICT to form authentic teaching and learning schoolroom experiences.

\section{Recommendations}

Based on the findings and discussions presented in preceding chapters many recommendations are offered. Future research is needed to verify the effectiveness of the following recommendations:

1. The school principals should play their role in promoting ICT in their school. Proper classes should be arranged for the students.

2. Proper timetable must be made. In that timetable class time should be separate from practical classes. There is no need to include theory and practical class timing together.

3. Theory class time can be of one hour and practical class time can be of at least two or three hours, so that the students can easily use the computers in the labs and can perform their practical work easily.

4. In the classroom teacher should try to use new technologies in the classroom so that students can learn more effectively and allow them to use it.

5. Computer subject teacher or IT teacher must know how to use computer in the classroom, what are the new technologies he or she can use and how can she or he use them.

6. If the teachers are comfortable in using laptop in the classroom then school's principal should allow her/him to use laptop in the classroom because laptop are more easy and simple to use them and they can easily carry them.

7. There must be a system of check and balance upon both teacher and students. Is teacher taking proper classes or not and is able to use new technologies in the classroom. And are students taking proper classes and are doing their work.

8. Teachers should try to display some videos in their class while giving lectures in classroom because video display will help them to understand lecture properly. 


\section{References}

Al-Ansari, H. (2006). Internet use by the faculty members of Kuwait University. The Electronic Library Vol.24, No. (6), 791-803.

Bhardwaj, A. (2016). Importance of education in human life: A holistic approach. International Journal of Science and Consciousness, 2(2), 23-28.

Davis, N.E., \& Tearle, P. (Eds.). (1999). A core curriculum for telematics in teacher training. www.ex.ac.uk/telematics.T3/corecurr/tteach98.htm

Hasan, T., \& Sajid, A. (2012). ICTs in learning in Pakistan. International Journal of Evaluation and Research in Education, 1(2), 51-60.

Januizewski, A., \& Molenda, M. (2008). Educational technology: A definition with commentary. New York: Lawrence Erlbaum Associates.

Jhurreev, V. (2005). Technology Integration in Education in Developing Countries: Guidelines to Policy Makers. International Education Journal [Electronic], 6(4):467483.

Lemke, C., \& Coughlin, E.C. (1998). Technology in American schools. www.mff.org/pnbs/ME158.pdf.

Noor-ul-Amin, S. (2013). An Effective use of ICT for Education and Learning by Drawing on Worldwide Knowledge, Research, and Experience. ICT as a Change Agent for Education. India: Department of Education, University of Kashmir.

OECD (2019), OECD Skills Outlook (2019). Thriving in a Digital World, OECD Publishing, Paris, https://dx.doi.org/10.1787/df80bc12-en.

Ratheeswari, K. (2018). Information communication technology in education. Journal of Applied and Advanced research, 3(1), 45-47.

Toffler, Alvin. (1991). Powershift: knowledge, wealth, and violence at the edge of the 21st century. Bantam Books

Tinio, L. Victoria. (2003). ICT in Education. New York: UNDP-APDIP.

Xiong, Z. (2020). Literature review of technology pedagogical and content knowledge (TPACK) (working document).

Yusuf, M.O. (2005). Information and communication education: Analyzing the Nigerian national policy for information technology. International Education Journal, Vol. 6 No. (3), 316-321 